\title{
The Prevalence of Addiction to Social Networking Sites and Its Impact on Well-Being among Students of Addis Ababa University, Ethiopia
}

\author{
Aman Ayza Alaro \\ Psychology Department, Wolaita Sodo University, Ethiopia \\ P.O.Box 138, Wolaita Sodo University, Ethiopia
}

\begin{abstract}
The research was self-sponsored and the researcher hasn't received financial support from external bodies. Abstract

The emergence of Social Networking Sites (SNS) has been changing many aspects of the students' daily activities positively. But, inappropriate use of social networking sites may have negative effects like Social Networking Sites Addiction (SNSA) and disturbance of psychological and social well-being. The purpose of this study was to assess the prevalence of SNSA and its impact on well-being among Addis Ababa University, Main Campus students. A cross-sectional research design was employed to collect and analyse data for the study. Simple random sampling technique was used to select participants from the colleges. Two hundred nineteen (290) samples (141 males and 132 females) were selected from the total 1,143 3rd year students in the Campus. A standardized and pilot tested questionnaire was used to collect the data. Descriptive statistics such as percentage and frequency, independent samples t-test, ANOVA, Pearson's Product-Moment correlation coefficient and linear regression were employed to analyse the data. The finding revealed that majority of the respondents was at the age of $21-25$. All of the participants included in the analysis were a member of at least one SNS and most of them access SNS several times per day. According to the findings, 3.3\% of participants were severely addicted to SNS and there is no gender difference in SNSA. The findings also showed that there was a statistically significant negative correlation between SNSA and both Psychological and Social Well-being. Moreover, recommendations were drawn based on the findings of the study.
\end{abstract}

Keywords: Addiction, Prevalence, Social Networking Sites, Well-being

DOI: $10.7176 / \mathrm{NMMC} / 95-01$

Publication date: January $31^{\text {st }} 2021$

\section{Introduction}

The beginning of social networking sites (SNS) goes back to late $19^{\text {th }}$ century. During this period, many scholars tried to invent different SNS at different time. But, most of them lacked popularity and failed at their earlier stages, whereas few of them became popular and still influential. Currently, the numbers of users of these popular SNS and the time spent on them by the users have been increasing. Researchers argue that increased time spent on SNS lead the users to Social Networking Sites Addiction (SNSA) and which in turn affects the well-being of the users (Andreassen \& Pallesen, 2014; Andreassen, 2015).

The beginning of SNS dates back to 1997. The first SNS, SixDegrees developed as a result of the idea that people were linked via six degrees of separation (Boyd and Ellison, 2008; Milgram, 1967). Using Six Degrees, its members could develop their personal profiles, create friend lists, and explore other friends' lists. Around 2000, the founder was declared that the site was shut down because of lack of adequate members. After its shutdown, several social networking sites, for example; Asian Avenue, Black Planet, MiGente, Match.com and Live Journal were emerged worldwide. Some of them launched at early $2000 \mathrm{~s}$, but none got enough popularity. That resulted in foundation of Friendster in 2002. Friendster originally designed to compete with Match.com, it grew into a great social networking site where subscribers can possibly network within their acquaintanceship and meet friends of friends. The site became highly popular and got recognized by the media in early 2003 (Boyd \& Ellison, 2007). A large membership flew as a result of the media coverage overwhelmed the site and at last, the site's fame weakened.

From the start of recognition of mainstream Medias like radio \& TV in 2003, many new social networking sites were created, the most successful of which is Facebook. Facebook was launched as an online community for students at Harvard University in 2004 by Mark Zukerberg (Kuss and Griffiths, 2011). Although there were newly emerging SNS with new features, Facebook was dominated by $79 \%$ users among the total number of social network sites' users in global level (Pew Research Center, 2016). Statistical Facts on Social Networks (2017) noted that among 2.34 billion social networks site users worldwide, $22.9 \%$ of the estimated world population were used Facebook in 2016.

The introduction of SNS i.e., Facebook in Ethiopia started in 2005, one year after the birth of Facebook (Tesfaye, 2013). Since its introduction, Facebook has attracted millions of users; many of them incorporated accessing the site in to their daily practice. Among the total Facebook users in the globe, Ethiopia is 12th in Africa and 80 th in the world. Besides this, the majority of its users were at the age of $16-24$ whom are living in the urban 
areas of the country (Socialbakers, 2014a). According to World Internet Statistics (2017), there are 4.5 million Facebook users with $4.3 \%$ penetration rate in Ethiopia. Among them, more than $50 \%$ of the Facebook users were found in the college and university education level.

Currently, the statistics shows that the number of SNS users and the time spent on SNS by users are growing in the world including Ethiopia. These increasing number of SNS users and the increasing time spent on SNS have becoming a source for many problems and a concern for many researchers across the globe to undertake studies in the area of psychology, technology and health. Different researchers revealed that increased time spent on SNS affect the well-being of users. According to Andreassen \& Pallesen (2014), a short time gratifying effects originated from social networking are unhealthy and addictive. Empirical finding further revealed that SNSA is related to impaired psychosocial health and wellbeing (Andreassen, 2015). Many researchers reported as there is a link between SNSA and depression and anxiety (Koc and Gulyagci, 2013; Hong et al., 2014) as well as poor psychosocial well-being (Valkenburg et al., 2006; Wilson et al., 2010 and Hong et al., 2014). Other research findings also showed as the offline relations with significant others suffer as the victims become preoccupied with and devote most of their time to virtual relationships through SNS (Elphinston and Noller, 2011; Çam and Isbulan, 2012). As a result of their preoccupation on SNS, the victims involve in conflict with family and friends and loss relationship with those significant people and lack collaboration of associates in their daily life. This affects the individuals' positive functioning in the environment.

Today, it is obvious that most of University students are equipped with different electronic devices. Internet services for these devices are also available in all Universities. So, students tend to use the devices like smartphone to access SNS everywhere at every time. They use it during a lecture hour while the teacher teaches, they surf it in library and lab rooms instead of reading and practicing educational materials, they use it in a coffee shop while drinking macchiato with friends whom met after a long time appointment, and they abuse it at dinner table while eating a dinner with families and friends. The availability of electronic devices and accessibility of internet services exposes the students to SNSA. The studies conducted in different parts of the world including Ethiopia have proved the presence of this problem (SNSA) in many countries (Folaranmi, 2013; Otu, 2015; Flacy, 2012; Hussain and Arasad, 2015 and Kirik et al., 2015). But, estimation of SNSA widely varies internationally. The study conducted in China on prevalence of SNSA in 2008 showed that 34\% of Chinese college students aged 19 to 28 suffered from SNSA (Wan, 2009). Similar study conducted in China by Huang (2011) discovered that 15.6\% of adolescents were classified as SNS addicts. According to Pempek et al. (2009), college students in USA use Facebook approximately $30 \mathrm{~min}$ per session and perceive Facebook as a part of their daily routine. The study conducted in Belgium showed that $6.5 \%$ of samples were SNS addicts. From Africa, the researches revealed that $1.6 \%$ of Nigerian University students were Facebook addicts (Folaranmi, 2013), and 1\% of Ghana University students were severely addicted to SNS (Otu, 2015). In addition to that, the scholars believes as the level of SNSA increase when daily time spent on the Internet increases, because frequent daily visits to social media profiles increase the level of addiction to SNS (Kirik et al., 2015). The survey conducted by socialbakers in 2013 showed that the adolescent Facebook users spent an average of 18 hours per month online in Ethiopia. In line with this, the total minutes spent on Facebook rose nearly 300\% in 2013 compared to 2012 (socialbakers, 2013).

Likewise, the study conducted in Nekemte Town, Oromia region of Ethiopia revealed that most of Ethiopian youths consume 30-60 minutes per session on SNS, and fall under "may be addicted" category (Hussain and Arasad, 2015). But there were no concrete evidences showing the prevalence of SNSA among University students and the impact of SNSA on well-being in Ethiopian context. Hence, it is important to investigate the prevalence of SNSA and its impact on psychological and social well-being among students in Ethiopian Universities. Therefore, this study sought to examine the prevalence of SNSA and its impact on psychological and social wellbeing among Addis Ababa University Main Campus students. The study also sought to find out the SNS the students were became a member and the reasons to be a member to those SNS. To realize these issues, the following basic research questions were answered:

1. What are the students most preferred SNS and why the students were tied up with these SNS?

2. What do the prevalence of SNSA among Addis Ababa University main campus students look like?

3. What are the impacts of SNSA on psychological well-being of students?

4. What are the impacts of SNSA on social well-being of students?

\section{Material and Methods}

\subsection{Research Design}

This study employed a cross-sectional research design in which self-administered open and close-ended questions were utilized. A cross-sectional design enables the researcher to compare the variables under investigation among different groups (a group of male and female students, students from different department, etc.). It was concerned both to describe what the present relationships are among variables in a given situation and to account for changes occurring in those relationships as a function of time. It also determines the relationships that exist between specific events (Cohen et al., 2005). 


\subsection{Study Area}

Addis Ababa University (AAU), which was established in 1950 as the University College of Addis Ababa (UCAA), is the oldest and the largest higher learning and research institution in Ethiopia. Since its inception, the University has been the leading center in teaching-learning, research and community services. Beginning with enrolment capacity of 33 students in 1950, AAU now has 47,610 students (29,872 undergraduate, 15,398 Master's and 2,340 $\mathrm{PhD}$ students). In its 15 campuses, the University runs 70 undergraduate and 293 graduate programs $(72 \mathrm{PhD}$ and 221 Masters), and various specializations in Health Sciences. Over 222,000 students have graduated from AAU since its establishment. Addis Ababa University, Main Campus (Sidist Killo) is found in Addis Ababa City. Addis Ababa City also known as Finfinne is the capital and largest city of Ethiopia. It is where the African Union is headquartered and where its predecessor the Organisation of African Unity (OAU) was based. It also hosts the headquarters of the United Nations Economic Commission for Africa (ECA), as well as various other continental and international organisations. The city lies a few miles west of the East African Rift Valley which splits Ethiopia into two, between the Nubian Plate and the Somali Plate. The city is a home for people from different regions of Ethiopia. It is a home to Addis Ababa University and holds 527 square kilometers of area in Ethiopia.

\subsection{Target Population of the Study}

The target population of this study was the Regular Undergraduate students of Addis Ababa University, Main Campus. Among the regular students, the researcher gave emphasis for $3^{\text {rd }}$ year students based on the assumption that 'when the year of stay in University increase, the probability of students to adopt technology and using SNS increases.' According to the data taken from the registrar of AAU, the total numbers of regular undergraduate students enrolled for 2017/2018 academic year within Main Campus were 4,910. Among them, the numbers of 3rd year students were 1,143. So, the target population comprised of 1,143 3rd year students enrolled for 2017/2018 academic year in all colleges and schools within Main Campus.

\subsection{Sample Size and Sampling Techniques of the Study}

According to Krejcie and Morgan (1970), for the population size of 1,143, the approximate samples of 290 were referred as appropriate at 95\% confidence level and 5\% margin of error and thus the researcher took 290 samples (150 males \& 140 females) for this study.

In this study, the researcher employed both probability and non-probability sampling techniques. Specifically, the purposive, simple random (lottery method), stratified and systematic random sampling techniques were used by researcher. Firstly, Addis Ababa University was selected purposively because of the countrywide blockage of internet services including SNS during data collection. At that time, internet service was blocked in all regions of the country except Addis Ababa City Administration due to elevated political crises. Secondly, among 15 campuses under Addis Ababa University, Main Campus was selected randomly through lottery method. All the colleges within Main Campus were taken as a sample by default. This is based on the researcher's assumption that students within different colleges may have different technology using knowledge and practices. Thirdly, one department from each college within Main Campus was selected randomly by using the simple random, lottery method. Fourthly, stratified sampling technique was applied to select proportional samples from the students based on their sex. Lastly, the researcher employed systematic random sampling technique to select representative samples for each sex. For that matter, the researcher collected the list of students from each college's registrar office and used sampling interval (SI) $=\frac{\mathrm{N}}{\mathrm{n}}$ formula to pick students for actual data. However, the researcher only analysed the data collected from a members of SNS to identify the prevalence of SNSA and its impact on students' psychosocial well-being.

\subsection{Data Gathering Instruments and Procedures}

This study employed self-administered questionnaire. The questions are of both open and close-ended types. The questionnaire consisted of five major parts: demographic questions, respondents' experiences of using SNS questions, level of SNSA scale, psychological well-being scale and social well-being scale. Demographic questions: included three questions about the Sex, Age and Department of the respondents. Respondents' use of SNS questions: included basic SNS accessing practices categorizing respondents as SNS users or not, user of many or few SNS, accessing SNS several times or rarely, and staying long or short hour per login. Social network sites addiction (SNSA) scale: which was adapted from Young's (1998) Internet Addiction Test (IAT) consisted of 20 questions wherein each item is scored using a six point Likert scale which required respondents to state their social networking sites behaviour based on the options: 0 , Never; 1, Rarely; 2, Occasionally; 3, Frequently; 4, Often and 5 , Always. The scale was composed of six sub-scales; salience with five items $\alpha=.83$, excessive use with five items $\alpha=.80$, neglect work with three items $\alpha=.67$, anticipation with two items $\alpha=.65$, lack of control with three items $\alpha=.74$ and neglect social life with two items $\alpha=.50$. The Cronbach's alpha of present study was .945 and that of the pilot study was .942 (see appendixes 3A and 3B). This instrument able to classify SNS user into four 
categories: normal users, mild addicts, moderate addicts and severe addicts. The scale was tested for validity and reliability in different parts of the world and the original scale yielded a good reliability level. It was chosen because SNS is a subtype of the internet and the items consisted in the IAT covers all sites unlike other tests that have been constructed for specific sites like Facebook Addiction Test. Psychological well-being scale: 18-items version of Ryff \& Keyes' Psychological Well-being scale was adapted and employed for this study (Ryff \& Keyes, 1995). Among 18 items, 6 with low internal consistency during pilot study were excluded from final questionnaire. The scale comprised of six subscales: autonomy (represented by one item), environmental mastery with two items $\alpha=.47$, personal growth with two items $\alpha=.55$, self-acceptance with three items $\alpha=.57$, purpose in life with two items $\alpha=.52$ and positive relation with others with two items $\alpha=.69$. Responses are made on a 5-point Likert scale from 1 , strongly agree to 5 strongly disagree. The subscales showed modest internal consistency in the present study, similar to the original Ryff and Keys (1995), ranging from .47 for the environmental mastery subscale to .69 for the positive relation with others subscale. The Cronbach's alpha of the scale for pilot study was .802 . The internal consistency of the combined 12-items scale in the presents study was .82 and this is also similar with that of original scale $(\alpha=.83)$. The scale included three negatively worded items. Social well-being scale: 15 items Keyes's (1998) model of SoWB scale was adapted and used. The responses for the scale are made on a 5-point Likert scale from 1, strongly agree to 5, strongly disagree. Among 15 items, 5 with law internal consistency during pilot study were discarded from final scale. The original scale consisted of three items in each of the sub-scales and that was changed in main study after pilot testing. The subscales with two or more items showed acceptable reliability in which social integration with two items $\alpha=.40$, social acceptance with three items $\alpha=.63$, social coherence with three items $\alpha=.52$ and the remaining two subscale; social contribution and social actualization was represented by one items each. The reliability of final 10 items during the pilot was .802 and that of the main study was .81, which is better than the alpha level of original social well-being scale, .74 . The final 10 -items scale has one negatively worded item.

Regarding data collection procedures, the researcher followed appropriate data collection steps to gather reliable and well-organized information from sample populations. The questionnaire was constructed and prepared in English first. Then, the pilot study was conducted and item analysis computed to check the validity and reliability of questionnaire. Before distributing the final questionnaire, the researcher was informed the objective of study and gained the consent from all the participants. Further, adequate orientations on how to respond the questionnaire was given to participants and participants filled the questionnaire in the presence of researcher and his assistant. The enough time which was estimated after pilot study was given to the participants to fill the questionnaire. The cooperation of instructors and class representative from each sample department was great. After data collection, the researcher has checked the completeness of the data and gave a code for each questionnaire and computed it using the SPSS V.20.

\subsection{Methods of Data Analysis}

Although $290(100 \%)$ of questionnaires were returned from the participants, $10(4.35 \%)$ of them were incomplete and discarded from analysis. Among the remaining 280 (95.65\%), 7 participants were not a member of SNS and also discarded from final analysis on the prevalence of SNSA and its impact on PWB and SoWB of students. The researcher selected only nine (9) severely addicted participants to examine the impact of SNSA on well-being. Then, the complete data of 273 participants was analysed by statistical package for social science (SPSS) Version 20. Before proceeding to the actual statistical analyses, assumptions associated with the use of each of the analysis were checked and all inverted items were reverse coded. After coding and entering the data in to SPSS, different statistical analyses were computed to summarize the raw data i.e. to see averages, variability and to express proportions of certain characteristics of the variables, descriptive statistics such as means, standard deviations, frequency and percentages were computed. To identify the interrelationship among the variables (SNSA and psychological and social well-being), correlation was computed. Moreover, Linear Regression analysis was computed to examine the impact of SNSA on students' psychological and social well-being. Data from openended questions was analysed thematically.

\subsection{Pilot Study}

To check the feasibility and adequacy of the questionnaire, pilot study was conducted. The original version of the instrument constructed in English was pilot tested on a selected sample of 42 participants ( 22 males and 20 females) from two randomly selected departments within AAU, School of Commerce Campus, which is not a part of the main study. Reliability of the questionnaire was measured by Cronbach Alpha using SPSS version 20. According to the criterion stated by George and Mallery, Cronbach's alpha $>.9$ Excellent, alpha $>.8$ Good, alpha $>.7$ acceptable (George and Mallery (2003). The Cronbach alpha of SNSA scale obtained during pilot study was .945 and that of the main data was .942. Thus, the scale showed excellent alpha level on both pilot and main studies and there were no deducted items from the original scale. The alpha value of original, 18-items psychological wellbeing scale during pilot study was .664 and after deducting 6 items with weak internal consistency, the scale 
yielded .802 level of alpha during pilot test with 12-items and this scale was used for actual study. The reliability level of the scale during main study was .82. Similarly, the 15 -items original social well-being scale was also pilot tested on 42 samples and yielded alpha value of .68. After eliminating 5 items with weak internal consistency, the reliability of entire 10-items scale yielded alpha level of .803 which is considered as good. Similarly, the scale yielded a Cronbach's alpha of .81 for actual study.

\section{Results}

This part sought to analyse the data using various statistical tools for different variables based on basic research questions. Firstly, descriptive statistics were used to analyse the demographic information, engagement to SNS and the prevalence of SNSA. Secondly, inferential statistics were applied to test age, department, frequency of accessing and average time spent on social networking site differences in Addiction among participants by making comparison of Post-hoc Tukey's test. Thirdly, the researcher employed Pearson's correlation coefficient to examine the relationships between SNSA and PWB, and SoWB. Lastly, linear regression was applied to examine the impact of SNSA on PWB and SoWB.

\subsection{Demographic Information of Participants}

Here the participants' demographic data was analysed by using descriptive statistics. To manage the data easily, the age of respondents was divided into four categories: 15-20, 21-25, 26-30 and 31 and above. According to the table 3.1 below, most of the respondents $(82.5 \%)$ were found within the age group of $21-25$ categories and the least $(2.1 \%)$ participants were found in the age category of 26-30. As presented in the table 3.1 below, the number of males was $141(51.6 \%)$ and females were $132(48.4 \%)$. Moreover, the participants were composed of eight different departments [Psychology (11\%), Law (16.8\%), English (9.5\%), Social Work (16.5\%), Archaeology $(11.4 \%)$, Broadcast Journalism (8.4\%), Linguistic (8.1\%) and Sociology (18.3\%)] within six colleges of Addis Ababa University, Main Campus.

Table 3.1:

Descriptive Statistics to Demographic Characteristics of participants (N Total $=280)$

\begin{tabular}{llcc}
\hline Demographic Variables & Characteristics & Frequency & Percent \\
\hline Sex & Male & 141 & 51.6 \\
& Female & 132 & 48.4 \\
& Total & $\mathbf{2 7 3}$ & $\mathbf{1 0 0}$ \\
\hline Age & $15-20$ & 42 & 15.4 \\
& $21-25$ & 226 & 82.5 \\
& $26-30$ & 5 & 2.1 \\
\hline Department & Total & $\mathbf{2 7 3}$ & $\mathbf{1 0 0}$ \\
& Psychology & 30 & 11.0 \\
& Enw & 46 & 16.8 \\
& Social work & 26 & 9.5 \\
& Archeology & 45 & 16.5 \\
& Broadcast & 31 & 11.4 \\
& Linguistics & 26 & 8.4 \\
& Sociology & 22 & 8.1 \\
& Total & 47 & 18.3 \\
\hline
\end{tabular}

Source: Survey, 2018

\subsection{The Students Preferred SNS and Their Intention to use SNS}

In this part, the students experience of SNS; whether the participants are a member of SNS or not, the types of SNS they have been using, the reasons why they have been engaged with SNS was analysed.

Table 3.2:

Descriptive Statistics to membership of social network sites $(N=280)$

\begin{tabular}{lrr}
\hline Are you a member of any of SNS? & Frequency & Percentage \\
\hline Yes & 273 & 97.5 \\
No & 7 & 2.5 \\
Total & $\mathbf{2 8 0}$ & $\mathbf{1 0 0}$ \\
\hline
\end{tabular}

Firstly, the researcher has tried to find out how many of the sample students were a member of SNS and how many of them were not. Accordingly, the table 3.2 above shows that most of the participants (97.5\%) were a member of SNS and few of them 7 (2.5\%) were not a member of SNS. In this research, those participants whom were not a member of SNS were discarded from the main analysis because of the research objective. Secondly, 
the researcher tried to find out the participants most preferred SNS. For this matter, the respondents whom were members of SNS further asked the types of SNS they have been using. According to the Table 3.3 below, Facebook and Telegram were the most preferred SNS by $80.6 \%$ of participants followed by WhatsApp $53 \%$ and Viber $51.6 \%$. The least preferred SNS, LinkedIn was familiar among $8.6 \%$ of participants. The analysis of data from open-ended question shown that Snap chat, we chat, Tinder, Pirates boy and torrent were commonly used SNS by some students.

Table 3.3:

\begin{tabular}{|c|c|c|}
\hline SNS & $\mathrm{N}$ & Percent of cases \\
\hline Facebook & 225 & $80.6 \%$ \\
\hline Twitter & 36 & $12.9 \%$ \\
\hline LinkedIn & 24 & $8.6 \%$ \\
\hline YouTube & 132 & $47.3 \%$ \\
\hline Telegram & 225 & $80.6 \%$ \\
\hline WhatsApp & 148 & $53.0 \%$ \\
\hline Viber & 144 & $51.6 \%$ \\
\hline Google + & 117 & $41.9 \%$ \\
\hline Imo Beta & 86 & $30.8 \%$ \\
\hline Messenger & 121 & $43.4 \%$ \\
\hline Skype & 33 & $11.8 \%$ \\
\hline Instagram & 119 & $42.7 \%$ \\
\hline & 1410 & $505.4 \%$ \\
\hline
\end{tabular}

a. Dichotomy group tabulated at value 1 .

*** Percent is greater than 100 because of multiple response analysis

In addition to the types of SNS being used by the participants, the researcher investigated the participants' intention of using those SNS. Although the intentions of students to be tied up with SNS may vary based on their interest and the multiple features of SNS, the researcher delimited the purposes to seven categories based on the findings of different studies. Based on these categories, the intention of using SNS among the participants was presented in the table 3.4 below.

Table 3.4:

Descriptive statistics to the intention of using SNS by students $(N=273)$

\begin{tabular}{lcc}
\hline Reasons of accessing SNS & N & Percent of cases \\
\hline To find information & 220 & $78.9 \%$ \\
For enjoyment & 164 & $58.8 \%$ \\
To keep in touch with family and friends & 155 & $55.6 \%$ \\
To make a new friends & 86 & $30.8 \%$ \\
To share experiences & 119 & $42.7 \%$ \\
To escape from bad feelings & 76 & $27.2 \%$ \\
For academic purposes? & 153 & $54.8 \%$ \\
Total & $\mathbf{9 7 3}$ & $\mathbf{3 4 8 . 7 \%}$ \\
\hline
\end{tabular}

a. Dichotomy group tabulated at value 1 .

$* * *$ Percent is greater than 100 because of multiple response analysis

As indicated in the Table 3.4 above, majority of participants (78.9\%) use SNS to find different information followed by $58.8 \%$ of responded using it for recreation and enjoyment. The least, $30.8 \%$ and $27.2 \%$ of participants responded as they use it to make new friends and to escape from bad feelings respectively.

\subsection{The Prevalence of Social Networking Sites Addiction}

To assess the prevalence of SNSA, firstly, the SNSA scale total score was computed and the score of each respondent for 20 items of SNSA scale was summed up and grouped in the ranges as stated by Young (1998). The scale's total score ranges from 0 to 100, with the higher the score representing the higher level of SNSA. Based on Young, a total score ranging from 0-30 points are considered a normal level of SNS usage, scores of 31-49 indicate the presence of a mild level of SNSA, 50-79 reflect the presence of a moderate level and scores of 80-100 indicate a severe SNSA (Young, 1998). Based on these ranges, 72(26.4\%) participants were normal SNS users, $116(42.5 \%)$ participants showed mild level of SNSA, $76(27.8 \%)$ of the participants were moderately addicted to SNS and the remaining 9(3.3\%) participants were severely addicted to SNS (see table 4.5 below). So, the 
researcher has used the severe addiction category as the prevalence of SNSA and used this category to examine its psychosocial impacts.

Table 3.5:

The prevalence of SNSA of respondents $(N=273)$

\begin{tabular}{llll}
\hline Ranges & Level of SNSA & N & Percent \\
\hline $0-30$ & Normal & 72 & $26.4 \%$ \\
$31-49$ & Mild & 116 & $42.5 \%$ \\
$50-79$ & Moderate & 76 & $27.8 \%$ \\
$80-100$ & Severe & 9 & $3.3 \%$ \\
Total & & $\mathbf{2 7 3}$ & $\mathbf{1 0 0 \%}$ \\
\hline
\end{tabular}

Secondly, the respondents' frequency of accessing SNS was analysed to complement with the analysis of data from SNSA scale. The table 3.6 below shows the summary of the findings of Frequency and corresponding Percentage of how often students access SNS. The table shows as 145(53.1\%) of participants have been accessing SNS several times per day, and only 2 participants responded as they open SNS once per month. The remaining 3 participants who have chosen "other" option in the questionnaire elaborated that "the frequency of accessing SNS depends on the situation and their mood". They responded that when they are free from workload, they use several times per day. If there were workloads like exam and assignment, they use once per week or two week. Some of the respondents said that: "It depends on the situation and my mood. Sometimes I use it several times per day, another time I use once per day." "It depends, (sometimes use once per day, another time I use within 2 days interval)."

Table 3.6:

Descriptive statistics of the frequency of accessing SNS by students $(N=273)$

\begin{tabular}{lrr}
\hline Frequency of accessing SNS & Frequency & Percent \\
\hline Several times per day & 145 & 53.1 \\
Once per day & 84 & 30.8 \\
Within 2 days interval & 11 & 4.0 \\
Once per 3 or 4 days & 18 & 6.6 \\
Once per Week & 10 & 3.7 \\
Once per Month & 2 & .7 \\
Other & 3 & 1.1 \\
Total & $\mathbf{2 7 3}$ & $\mathbf{1 0 0}$ \\
\hline
\end{tabular}

Finally, the researcher tried to assess the time spent on SNS per session as an indicator of SNSA. According to the table 3.7 below, among 273 (100\%) participants, 85(31.1\%) spent 30 - 1 hour per login on SNS, 48(17.5\%) spent 1-2 hours, 24(8.8\%) stay 3 and above hours per login and the remaining 9(3.3\%) participants responded as their situation determines the time they spent on SNS.

Table 3.7:

Descriptive statistics of the time spent on SNS per login by students $(N=273)$

\begin{tabular}{ccc}
\hline Time spent on SNS per session & Frequency & Percent \\
\hline $1-10^{\prime}$ & 57 & 20.9 \\
$11-30^{\prime}$ & 50 & 18.3 \\
$30^{\prime}-1 \mathrm{hr}$ & 85 & 31.1 \\
$1-2 \mathrm{hrs}$ & 48 & 17.6 \\
3 hrs and above & 24 & 8.8 \\
Other & 9 & 3.3 \\
Total & $\mathbf{2 7 3}$ & $\mathbf{1 0 0}$ \\
\hline
\end{tabular}

\subsubsection{Differences of SNSA in Terms of Demographic Variables, Frequency of Accessing and Time Spent on SNS}

Here the mean difference between two or more groups was computed through different statistical tools like independent t-test and One Way ANOVA. Each of the mean differences between the groups in terms of SNSA is presented as follows:

\subsubsection{Difference of SNSA in terms of Sex}

To check the level of SNSA in terms of sex (male and female), independent samples t-test was computed and presented in the table 3.8 below. 
Table 3.8:

\begin{tabular}{|c|c|c|c|c|c|c|c|c|c|c|c|}
\hline \multirow[t]{2}{*}{ SNSA } & \multicolumn{2}{|c|}{ Male } & \multicolumn{4}{|c|}{ Female } & \multirow{2}{*}{\multicolumn{2}{|c|}{$95 \%$ CI for MD }} & \multirow[b]{2}{*}{$r$} & \multirow[b]{2}{*}{$t$} & \multirow[b]{2}{*}{$d f$} \\
\hline & $M$ & $S D$ & $n$ & $M$ & $S D$ & $n$ & & & & & \\
\hline & 44.4 & 16.078 & 141 & 40.5 & 17.12 & 132 & -.074 & 7.84 & .054 & 1.93 & 271 \\
\hline
\end{tabular}

$\mathrm{P} *<.05$

The result in the table 3.8 above shows that there was no significant difference in score between the groups of males $(\mathrm{M}=44.4, \mathrm{SD}=16.08, \mathrm{n}=141)$ and females $(\mathrm{M}=40.5, \mathrm{SD}=17.12, \mathrm{n}=132)$ at .05 level of significance $\mathrm{t}(271)=1.93, \mathrm{p}=0.054,95 \% \mathrm{CI}[-.074$ to 7.84$]$. The magnitude of difference in the means (mean difference $=$ 3.88 , CI: -.074 to 7.84 ). So, the level of SNSA was not varied between male and female students of AAU, Main Campus. This indicates that both males and females were equally engaged to SNS in their day-to-day activities and they were equally exposed to SNSA. Additionally, the researcher also computed the independents samples ttest to compare the mean difference between males and females regarding both the frequency of accessing and the average time spent on SNS. As indicated in the table 3.9 below, there is no statistically significant difference between males and females regarding the frequency of accessing SNS. Inspection of the two group means indicates that the frequency of accessing SNS score for males $(\mathrm{M}=1.84, \mathrm{SD}=1.27, \mathrm{n}=141)$ and females $(\mathrm{M}=1.71, \mathrm{SD}=$ $1.05, \mathrm{n}=132)$ at $\mathrm{p}<.05, \mathrm{t}(271)=.935, \mathrm{p}=.35,95 \% \mathrm{CI}[-.146$ to .41$]$.

Table 3.9:

Independent Samples t-test for difference on frequency of accessing SNS in sex

\begin{tabular}{llllllllllll}
\hline $\begin{array}{l}\text { Frequency } \\
\text { of using }\end{array}$ & \multicolumn{1}{c}{ Male } & \multicolumn{9}{c}{ Female } & \multicolumn{7}{c}{$95 \%$ CI for MD } & $r$ & $t$ & $d f$ \\
\hline & $M$ & $S D$ & $n$ & $M$ & $S D$ & $n$ & & & .35 & .935 & 271 \\
\hline & 1.84 & 1.27 & 141 & 1.71 & 1.05 & 132 & -.146 & .41 & .35 \\
\hline
\end{tabular}

$\mathrm{P}^{*}<.05$

Similarly, the result presented in the table 3.10 below shows that average time spent on SNS for males $(\mathrm{M}=$ 2.70, $\mathrm{SD}=1.320, \mathrm{n}=141)$ and females $(\mathrm{M}=3.02, \mathrm{SD}=1.340, \mathrm{n}=132), \mathrm{p}<.05, \mathrm{t}(271)=-1.966, \mathrm{p}=.05,95 \% \mathrm{CI}$ [-.641 to .000]. This indicates that the average time spent on SNS by males and females was not different.

Table 3.10:

Independent Samples t-test for difference of time spent on SNS per session by sex

\begin{tabular}{llllllllllll}
\hline Time spent & Male & \multicolumn{1}{c}{ Female } & \multicolumn{1}{c}{$95 \%$ CI for MD } & & & \\
on SNS & $M$ & $S D$ & $n$ & $M$ & $S D$ & $n$ & & & $r$ & $d f$ \\
\hline & 2.7 & 1.32 & 141 & 3.02 & 1.34 & 132 & -.641 & .000 & .05 & -1.966 & 271 \\
\hline
\end{tabular}

$\mathrm{P}^{*}<.05$

\subsubsection{Difference of the SNSA in terms of Age}

To examine the mean difference among the age categories of respondents, the researcher computed one way ANOVA. As indicated in the Table 3.11 below, ANOVA showed no statistically significant difference at $p>.05$ for SNSA for three age groups $(15-20,21-25$ and 26-30): $F(2,270)=1.538, p=.217, \eta 2=.011$. This indicates that all age groups of the students were equally using SNS in their daily life.

Table 3.11:

One-Way ANOVA for level of SNSA by Age Categories

\begin{tabular}{lrrrrrr}
\hline \multicolumn{1}{c}{ Age } & \multicolumn{1}{c}{$S S$} & $d f$ & $M S$ & $F$ & $p$ & $\eta 2$ \\
\hline Between Groups & 851.885 & 2 & 425.943 & 1.538 & .217 & .011 \\
Within Groups & 74796.320 & 270 & 277.023 & & & \\
Total & 75648.205 & 272 & & & & \\
\hline
\end{tabular}

\subsubsection{The Difference of SNSA in terms of the Frequency of using SNS}

To see the difference of SNSA in terms of the frequency of using SNS, the researcher computed One Way ANOVA and result shows the statistically significant difference at the $p<.05$ level in frequency of using SNS as the groups: $F(5,267)=4.292, p=.001, \eta 2=.074$ (see table 3.12 below). Post-hoc comparisons using the Tukey HSD test indicated that the mean score for participants accessing SNS several times per day $(M=46.245, S D=17.75)$ was significantly different from participants accessing SNS once per day $(M=39.674, S D=14.69889)$. The mean score of participants accessing SNS several times per day was significantly different from participants accessing SNS once per day; means that the mean of students using SNS several times per day is greater than that of their counterparts whom uses SNS once per week. So, participants accessing SNS several times per day were more addicted than participants accessing SNS once per day. 
Table 3.12:

One-Way ANOVA for SNSA by Frequency of accessing SNS

\begin{tabular}{|c|c|c|c|c|c|}
\hline Frequency of accessing SNS & $S S$ & $d f$ & $M S$ & $F$ & $\begin{array}{ll}p & \eta 2 \\
\end{array}$ \\
\hline Between Groups & 5 & 5627.616 & 1125.523 & 4.292 & .001 .074 \\
\hline Within Groups & 267 & 70020.59 & 262.249 & & \\
\hline Total & 272 & 75648.20 & & & \\
\hline
\end{tabular}

\subsubsection{The difference of SNSA in terms of average time spent on SNS}

To examine the mean difference between the groups of participants categorized as accessing SNS 1-10 minutes to $\geq 3$ hours per session, the researcher computed One Way ANOVA. The result of ANOVA presented in the table 3.13 below shows that there is statistically significant difference between the groups at $p<.05$ by average time spent on SNS per session: $F(5,267)=6.392, p=.001, \eta 2=.107$. The Post-hoc comparisons using the Tukey HSD test indicated that the mean score for participants staying $1-10$ minutes on SNS per session $(M=36.65, S D=$ 15.82) was significantly different from participants staying $1-2$ hours on SNS $(M=49.85, S D=18.245)$ and respondents staying 3 hours and above on SNS per login $(M=50.167, S D=18.75)$. Similarity, the mean score of participants staying $11-30$ minutes on SNS once logged in $(M=36.46, S D=12.94)$ was statistically different from those staying $1-2$ hours on SNS $(M=49.85, S D=18.245)$ and students staying 3 hours and above on SNS per login $(M=50.167, S D=18.75)$.

Table 3.13:

One-Way ANOVA of the Level of SNS addiction in terms of time spent on SNS

\begin{tabular}{lllllll}
\hline Time spent on SNS & $d f$ & $S S$ & $M S$ & $F$ & $p$ & $\eta 2$ \\
\hline Between Groups & 5 & 8086.667 & 1617.333 & 6.392 & .000 & .107 \\
Within Groups & 267 & 67561.54 & 253.039 & & & \\
Total & 272 & 75648.2 & & & & \\
\hline
\end{tabular}

\subsubsection{The Difference of SNSA in Terms of Departments}

Concerning the difference of SNSA in terms of department, the researcher also computed One Way AVOVA and the result of ANOVA in the table 3.14 below showed that there is no statistically significant difference at $p>.05$ in SNSA between the participants in their department: $F(7,265)=1.631, p=.127, \eta 2=.041$.

Table 3.14:

One-Way ANOVA of the Level of SNA in terms departments

\begin{tabular}{lllllll}
\hline Departments & $d f$ & $S S$ & $M S$ & $F$ & Sig. & $\eta 2$ \\
\hline Between Groups & 73 & 124.34 & 446.334 & 1.631 & .127 & .041 \\
Within Groups & 265 & 72523.87 & 273.675 & & & \\
Total & 272 & 75648.5 & & & & \\
\hline
\end{tabular}

\subsection{Impacts of SNSA on Psychological Well-Being (PWB)}

\subsubsection{Correlation of SNSA and PWB}

Before investigating the impact of SNSA on psychological well-being, the researcher computed the Pearson's correlation coefficient to check the relationship between variables; SNSA and PWB. As presented in the table 3.15 below, there is statistically significant correlation between general SNSA and psychological well-being at $\mathrm{p}<.01$, $r(9)=-.300, p=-.001$. The result shows that there is a negative relation between SNSA and PWB. This means, as the level of SNSA increases, students' psychological well-being decreases.

Table 3.15:

Pearson Product-Moment Correlations of the SNSA and PWB (N=9)

\begin{tabular}{llrr}
\hline & & SNSA & PWS \\
\hline \multirow{2}{*}{ SNSA } & Pearson Correlation & 1 & $-.300^{* *}$ \\
& Sig. (2-tailed) & & -.0001 \\
\multirow{2}{*}{ PWS } & Pearson Correlation & $-.300^{* *}$ & 1 \\
& Sig. (2-tailed) & -.0001 & \\
\hline
\end{tabular}

$* * \mathrm{p}<.01$ (2-tailed).

\subsubsection{Regression Analysis}

To determine the impact of SNSA on PWB, the researcher computed linear regression analysis. As shown in the table 3.16 below, the result is statistically significant, $\mathrm{F}(1,9)=-26.8, \mathrm{p}<.001$. The identified equation to understand this relationship was PWB $=23.832+0.114 \times$ SNSA. The adjusted $R^{2}$ value was -.090 . This indicates that $-9 \%$ of the variance in PWB was explained by the SNSA. The sig. value against SNSA is less than 0.05 and negative; there is significant evidence to suggest that the SNSA negatively affects the PWB. Even though SNSA negatively affects PWB, according to Cohen (1988), its effect (-.09) is very low. The slope coefficient for SNSA was -0.114 , so that the PWB of students decreases by 0.114 when SNSA increase. The result also indicates that 
$91 \%$ of the variation is still unexplained.

Table 3.16:

Linear regression Coefficients for the impact of SNSA on PWB

\begin{tabular}{llllllll}
\hline Variable & $B$ & $S E B$ & $\beta$ & $R$ & $R 2$ & $F$ & $P$ \\
\hline PWB & 23.832 & 1.004 & & .300 & -.090 & 26.8 & -.0001 \\
SNSA & -.114 & .022 & .300 & & & & \\
\hline
\end{tabular}

Predictors: SNSA

Dependent Variable: PWS

\subsection{Impacts of SNSA on Social Well-Being (SoWB)}

\subsubsection{Correlation of SNSA and SoWB}

Before computing regression analysis to investigate the impact of SNSA on SoWB, the researcher tried to see the association between SNSA and SoWB by using the Pearson correlation coefficient. So, the table 3.17 below showed that there is a statistically significant correlation between general SNSA and SoWB at $p<.01, r(9)=.20$, $p=-.001$. The result shows that there was a negative relationship between SNSA and SoWB. This means that while the level of SNSA increases, SoWB of students decreases.

Table 3.17:

Pearson Product-Moment Correlations of the SNS addiction and SoWB $(N=9)$

\begin{tabular}{llrr}
\hline & & SNSA & SoWB \\
\hline \multirow{2}{*}{ SNSA } & Pearson Correlation & 1 & $.197^{* *}$ \\
& Sig. (2-tailed) & & -.001 \\
\multirow{2}{*}{ SoWB } & Pearson Correlation & $.197^{* *}$ & 1 \\
& Sig. (2-tailed) & -.001 & \\
\hline
\end{tabular}

\subsubsection{Regression Analysis}

To examine the impact of SNSA on SoWB, the researcher computed linear regression analysis. According to the regression summery table 3.19 below, the results was statistically significant, $F(1,9)=10.93, p=-.001$. The sig value against SNSA is less than 0.05 and negative; there is significant evidence to suggest that SNSA negatively affected SoWB. The identified equation to understand this relationship was SoWB $=21.92+-0.066 \times$ SNSA. The slope coefficient for SNSA was -0.066 , so that the SoWB of students decreases by 0.066 when SNSA increase. The adjusted $R^{2}$ value was -.04 . This indicates that $4 \%$ of the variance in SoWB was explained by the SNSA. According to Cohen (1988), this has a low effect.

Table 3.18:

Linear regression Coefficients for the impact of SNS addiction on SoWB

\begin{tabular}{llllllll}
\hline Variable & $B$ & $S E B$ & $\beta$ & $R$ & $R 2$ & $F$ & $P$ \\
\hline SoWB & 21.92 & .911 & & .300 & .090 & 10.93 & -.001 \\
SNSA & -.066 & .020 & .197 & .197 & -.04 & & \\
\hline
\end{tabular}

Predictors: SNSA

Dependent Variable: SoWB

\section{Discussion}

Today, a numbers of social networking sites (SNS), their users and the time spent on SNS by users have been rising. This increment is becoming a source for many problems and a concern for many researchers across the globe in different disciplines. Based on this concern, this study investigated the prevalence of Social Networking Sites Addiction (SNSA) and whether it affected psychological and social well-being of the students negatively or positively.

To confirm these, firstly, the study was aimed to assess the students most preferred SNS and reasons of using SNS. Accordingly, the study revealed that Facebook and Telegram were the most popular SNS among AAU main campus students, equal $80.6 \%$ of students use them. Some of the respondents mentioned as they have been using other SNS like Snapchat, WeChat, Tinder and Pirets boy. These findings are consistent with the previous study conducted by Dau (2015). His study indicated that majority of the respondents use almost all popular social network platforms and Facebook was also highly popular among them (Dau, 2015). The point of difference is that both Facebook and Telegram were equally popular according the finding of current study while Dau (2015) identified only Facebook as having the largest number of users in previous study. The reason for this difference might be the newness of Telegram. Although the finding revealed that Facebook and Telegram were the most regularly used SNS, all the respondents had alternatives. This finding is based on the assumptions of the Uses and Gratification theory, which explains that there is a motive for each user to choose and use a Medias that satisfies 
the need. According to this theory, media consumers have a freedom to choose from a variety of channels. So, the finding shows as Facebook and Telegram gratified the users more than other SNS. Additionally, the findings was also supported by the Media Systems Dependency Theory, which posits that the more a SNS fulfils the needs of a user, the more dependent the user is on that media. Therefore, students access Facebook and Telegram more frequently because they fulfilled their need more than other SNS.

Regarding the reasons why students have been using SNS so far, study found that majority of respondents access SNS to find different information. This indicates that students are using SNS purposively for searching of new information instead of following mainstream Medias. Other reasons includes but not limited to enjoyment, to keep in touch with others, for academic purpose, to share experience with others, to make new friends and to escape from bad feelings. These findings are consistent with that of Otu (2015), which revealed that majority of students used SNS for entertainment and information purposes, Appeanti \& Danso (2003), revealed that majority of the students use SNS mainly for social issues such as friendship and communication and Majias (2005), reported as people use SNS for exchanging information, expressing, creating and keeping spontaneous social interactions and to strengthen non - formal learning practices.

Concerning the frequency of using SNS, present study found that more than half $(53.1 \%)$ of the respondents access SNS several times per day, 30.8\% of students surf SNS on daily bases and others access SNS once within few (2 and 3) days. This finding was supported by some other studies (Folaranmi, 2013 and Hussain \& Arasad, 2015). The study conducted in Nigeria revealed that many undergraduate students access Facebook every passing hour, every two hours and every day (Folaranmi, 2013). The study conducted in Nekemte Town of Western Ethiopia on the prevalence of SNSA among youths revealed that most of the youths visit their social network accounts once in a few days (Hussain \& Arasad, 2015).

Regarding the amount of time spent on SNS per login, the finding showed as the majority of participants spent 30 minutes to 1 hour followed by participants spending less than 30 minutes. This finding is also consistent with the findings of Hussain \& Arasad (2015) which revealed as most of the youths stayed $30-60$ minutes per session on SNS. This further confirms the presence of SNSA among students as time spent on social media has been identified as an indicator of addiction (Al-Menayes, 2015). Al-Menayes (2015) conducted the study in University of Derby in UK on social media addiction and sated as the users who spent an average of 3.6 hours per day on SNS are classified as addicted. Thompson and Loughleed (2012) study also revealed that undergraduate students spent almost 2 hours on SNS in general and 106 minutes on Facebook in particular.

Moreover, concerning one of the main objectives of the study; assessing the prevalence of SNSA, the finding confirmed as the phenomenon exist at different level (mild through medium to severe addiction) among the students. The finding showed that $3.3 \%$ of participants were severely addicted to SNS and $26 \%$ of the respondents were normal SNS users. This was supported by the findings of Huang's (2011) study conducted among adolescents in China; which discovered as $15.6 \%$ of respondents were classified as SNS addicts. The result also confirms the findings of Otu (2015) and Folaranmi (2013), in which majority of respondents were mild to moderately addict and a small number of participants were severely addicted to SNS. Both of them revealed 1 to $1.6 \%$ level of SNSA among university undergraduate students.

Concerning the difference of SNSA in terms of sex, age, frequency of accessing and time spent on SNS, the study revealed that; (1) there is no statistically significant difference in score between the groups of males $(M=$ $44.4, S D=16.08, n=141)$ and females $(M=40.5, S D=17.12, n=132)$ at .05 level of significance $t(271)=1.93$, $p=0.054>\alpha=0.05,95 \%$ CI [-.74 to 7.84$]$. This was supported by the study conducted in Turkey on 271 students by Kirik et al. (2015) on the level of social media addiction among young people. The study witnessed as there is no significant difference in level of social media addiction between female and male participants $(X$ Female $=78.92$; $X$ Male $=79.99 ; t=0.406 ; P>0.05)$. (2) There is no statistically significant difference at the $p>.05$ level in SNSA for three age groups: $F(2,270)=1.538, p=.217, \eta 2=.011$. This finding contradicts with the finding of Kirik et al. (2015) as they discovered a significant difference in social media addiction for different age groups $(F=6.256$; $P<0.05$ ). (3) the study revealed a statistically significant difference among the groups categorized as surfing several times per day, accessing once per day, accessing one per 2 or 3 days, accessing once per week and accessing once per month: $F(5,267)=4.292, p=.001, \eta 2=.074$, as computed from One way ANOVA. Post-hoc comparisons using the Tukey HSD test computed indicated that the mean score for participants accessing SNS several times per day $(M=46.245, S D=17.75)$ was significantly different from participants accessing SNS once per day $(M=39.674, S D=14.69889)$. This means, participants accessing SNS several times per day were more addicted than participants accessing SNS once per day. The result was also supported by the finding of Kirik et al. (2015), which stated as the frequency of visiting social media $(\mathrm{F}=53.56 ; \mathrm{P}<0.05)$ make significant differences in addiction level. (4) There is a statistically significant difference at $p<.05$ by average time spent on SNS once logged in: $F(5,267)=6.392, p=.001, \eta 2=.107$. As computed from post hoc tukey's test, participants staying $\geq 3$ hours per session were more addicted than participants staying $1-10$ minutes on SNS per login. This finding was also consistent with the finding of Kirik et al. (2015), which found a significant difference between social media addiction levels of people who spend different amounts of time on the social media $(F=44.036 ; P<0.05)$ 
and concluded as social media addiction level increases dramatically as daily time spent on it increases.

The third main objective of the study was to investigate the impact of SNSA on psychological wellbeing among undergraduate students, and the result showed the statistically significant negative correlation for psychological well-being [sig. (2-tailed) $=-.001$ ] at correlation significant at $p=0.01$ for the students' SNSA with PWB: $r(9)=-.300, p=-.001$. The linear regression analysis computed to examine the impact of SNSA on PWB revealed as the results were statistically significant at $F(1,9)=26.8, p<.001$. The identified equation for this impact was $\mathrm{PWB}=23.832+(-0.114) \times$ SNSA. The adjusted $R^{2}$ value was -.090 . This indicates that $-9 \%$ of the variance in PWB was explained by the SNS addiction. The finding was supported by several studies. For example, Johnson (2004) and You (2007) described on their study as negative online experiences were highly correlated with a variety of negative psychological states. The study conducted by Kross and his colleagues identified that Facebook dependence increases the negative feelings among young adults become worse over time and the life satisfaction level declined from the baseline measurement over the two week period. Participants' moment-tomoment feelings declined as well with more Facebook use (Kross et al., 2013). The study in Belgium also revealed as the samples who were using SNS compulsively showed lower scores on measures of emotional stability, conscientiousness, perceived self-esteem, and higher scores on depressive feelings (Tsitsika et al., 2015; Wang et al., 2015 \& DeCock et al., 2014). Other study also described a compulsive SNS dependence leads to significant psychological problems like distress, anxiety, and symptoms of depression (Çam \& Isbulan, 2012; Elphinston \& Noller, 2011).

The fourth and final objective of this study was to examine the impact of SNSA on social well-being (SoWB) of students, and the Pearson correlation result showed a statistically significant correlation for SoWB [sig. (2tailed $)=-.001], \mathrm{p}<.01, \mathrm{r}(9)=.2, \mathrm{p}=-.001$ at significance level of 0.01 . This shows as there is a negative relation between SNSA and SoWB. This means when SNSA increases, the SoWB decreases. Similarly, the linear regression analysis computed to examine the impact of SNSA on SoWB showed a significant result as F $(1,9)=$ $10.93, \mathrm{p}=-.001$. The sig value against SNSA is less than 0.05 and negative; there is a significant evidence to suggest that SNSA negatively affects the SoWB. The identified equation to understand this relationship was SoWB $=21.92+(-0.066) \times$ SNSA. The slope coefficient for SNSA was -0.066 , so that the SoWB of students decreases by -0.066 when SNSA increase. The adjusted $R^{2}$ value was -.04 . This indicates that $-4 \%$ of the variance in SoWB was explained by the SNSA. This study confirms previous findings that greater SNS dependence is associated with decreased offline social capital and increased loneliness. The finding was supported by the result of Kraut et al., (1998), which showed that compulsive SNS use significantly affects social relationships and participation in community life. In their study, Kraut et al. stated as increased time spent online leads to a decline in communication with family members and the reduction of the technology user's social circle. The finding was also supported by the study of Çam \& Isbulan (2012) and Elphinston \& Noller (2011). Both of them stated as compulsive SNS dependence leads to significant social problems such as negatively relationships at home (family conflicts), at work (impaired concentration and collaboration), and social isolation (loss of friends). The research conducted in Belgium also revealed as the samples with SNSA have higher scores on loneliness (Tsitsika et al., 2015; Wang et al., 2015 \& DeCock et al., 2014).

\section{Conclusion}

This research was investigated the prevalence of SNSA and its impact on PWB and SoWB among AAU, Main

Campus Students. Based on the main findings of the study, following conclusions were made:

1. Facebook and Telegram were the most prepared SNS among the students to find information, for recreation, to keep in touch with others and for academic purposes.

2. It was evident that SNSA exists among AAU; Main Campus students, i.e., 3.3\% of students were severely addicted to SNS.

3. Regarding SNS usage and the level of its addiction, students using SNS several times per day and staying $\geq 30$ minutes on SNS per session were more addicted than other categories.

4. There was a negative correlation between SNSA and both psychological and social well-beings of the participants.

5. The finding also revealed that the SNSA negatively affected both psychological and social well-being of AAU students.

\section{Recommendations}

Based on the findings of the study, the researcher forwarded some recommendations to the concerned bodies as follows:

1. Students need to be wise when using SNS so as not too dependent on SNS and not to miss out the fundamentals of real world, face-to-face interactions.

2. AAU should design and implement awareness campaigns on weak sides of SNS.

3. Formulating and executing rules governing the students' use of SNS in the Campus is important. 
4. The study focused only on AAU, Main Campus students. So, related studies should be carried out within wider area.

5. Participants are reluctant to give true information for sensitive issues like addiction. They perceive as the researcher judge them based on the information they give. So, conducting experimental research instead of survey may give genuine result.

\section{Funding}

This study was sponsored by the author himself.

\section{Acknowledgements}

Everything has not been smooth throughout this journey but Almighty God has been helped me a lot, praise and thanks to God. My wife, Kuchi, understood my situation when I was busy and helped me in every aspects. So, I would like to provide my special and great thanks to her. Dr. Tigist Wuhib Tsega's guidance has a great value in accomplishment of this study. I have no words to thank her, my almighty God bless her immensely. My friend, Mr. Metasebiya Gonta contributed a lot for the success of this study. He is my special friend as well as brother. I would like to thank him a lot.

\section{Conflict of interest}

I declared that there is no conflict of interest with other authors and I assure that I am responsible for any problem that may arise.

\section{References}

Andreassen, C. S, Pallesen, S. (2014). Social network site addiction-an overview of the SNS addiction field in terms of definition, measurements, antecedents, consequences, interventions, and future research directions.

Andreassen, C. S. (2015). Online social network site addiction: A comprehensive review. Current Addiction Reports, 2(2), 175-184. http://doi.org/10.1007/s40429-015-0056-9

Boyd D.M., Ellison N.B. (2008). Social network sites: Definition, history, and scholarship. Journal of Computer Mediated Communication; 13, 210-230. Doi: 10.1111/j.10836101.2007.00393

Boyd, D., \& Ellison, N. (2007). Social network sites: Definition, history, and scholarship. Journal of ComputerMediated Communication, 13(12) 210-230. doi:10.1111/j.1083-6101.2008.01432.x

Çam, E., \& Isbulan, O. (2012). A new addiction for teacher candidates: social networks. Turkey Online Journal of Education and Technology.

Cohen, J. (1988). Statistical power analysis for the behavioral sciences (2nd ed.).Hillsdale, NJ: Lawrence Earlbaum Associates.

Cohen, L., Manion, L., \& Morrison, K. (2005). Research methods in education (5th ed). Taylor \& Francis eLibrary, New York

Elphinston, R. A., \& Noller, P. (2011). Time to face it! Facebook Intrusion and the Implications for Romantic Jealousy and Relationship Satisfaction. Cyber Psychology, Behavior \& Social Networking.

Flacy, M. (Feb 2012). Is Facebook more addictive than alcohol or cigarettes? Retrieved from: https://www.digitaltrends.com/social-media/study-is-facebook-more-addictive-than-alcohol-or-cigarettes/

Folaranmi, A. O. (2013). A Survey of Facebook Addiction Level among Selected Nigerian University Undergraduates. Department of Communication and Media Studies, Ajayi Crowther University, Oyo, P.M.B 1066 Oyo State, Nigeria: New Media and Mass Communication, ISSN 2224-3267 (Paper) ISSN 2224-3275 (Online); 10, 2013

Hong, F., Huang, D., Lin, H., \&Chiu S. (2014). Analysis of the psychological traits, Facebook usage, and Facebook addiction model of Taiwanese university students. Telematics Informat.

Hussain, S. \& Arasad, M. (2015). Prevalence of Social Networks Addiction among Ethiopian Youths. International Journal of Science and Research (IJSR); 4 (3), 834-837

Kirik, A. M., Arslan, A., Getinkaya, A., \& Gul, M. (2015). A Quantitative Research on the Level of Social Media Addiction among Young People in Turkey. International Journal of Science Culture and Sport (IntJSCS); 3(3), 2148-1148 Doi: 10.14486/IntJSCS444

Koc, M., \& Gulyagci, S. (2013). Facebook addiction among Turkish college students: The role of psychological health, demographic, and usage characteristics. Cyber Psychology, Behavior \& Social Networking

Krejcie, R. T., \& Morga N, D. W. (1970). Determining sample size for research activities. Educational and psychological measurement; 30, 607-610.

Kuss D.J., \& Griffiths M. D. (2011). Online social networking and addiction; A review of the psychological literature. International Journal of Environment Research on Public Health; (8)3528-3552. Doi: $10.3390 /$ ijerph 8093528 .

Milgram S. (1967). The small world problem. Psychology Today; 2, 60-67. 
Otu, A. A. (2015). Social Media Addiction among Students of the University of Ghana; Senior Essay (Unpublished)

Pew Research Center. (2010). Pew Internet \& American Life Project. Retrieved from http://pewinternet.org/Reports/2010/Generations-2010.aspx

Socialbakers. (March, 2014). Ethiopian Facebook users' demographic statistics. Retrieved from http://www.socialbakers.com/facebook-statistics/ethiopia

Statistical Facts on Social Networks. (October, 2017). Retrieved from: https://www.statista.com/topics/1164/social-networks

Statistical Most Famous Social Network Sites Worldwide. (October, 2017). As of September 2016, Ranked by Number of Active Users.

Tesfaye, A. (2013). Social media as an alternative political forum in Ethiopia: the case of Facebook (Master thesis), Addis Ababa University.

Valkenburg, P. M., Peter, J., \& Schouten, A. P. (2006). Friend networking sites and their relationship to adolescents' well-being and social self-esteem. Cyber Psychology\& Behavior, 9(5), 584-590. http://doi.org/10.1089/cpb.2006.9.584

Wilson, K., Fornasier, S., \& White, K.M. (2010). Psychological predictors of young adults' use of social networking sites. Cyber psychology, Behavior and Social Networks.

Young, K. S. (1998). Internet addiction: The emergence of a new clinical disorder. Cyber Psychology and Behavior; 1(3), 237-244. 